\title{
The Technique of Evaluating Anti-leprosy Medications at the Forschungsinstitut Borstel
}

\author{
E. FREERKSEN
}

Forschungsinstitut Borstel, 2061 Borstel, West Germany

I should like to demonstrate only a few results selected from a great number of experiments, and explain several principles which finally made us prefer a certain form of chemotherapy. Mr Alvarenga, Mrs Aschoff and Messrs Depasquale, Hamzah, Krenzien and Rohde will each read a paper about their practical results tomorrow.

(1) Leprosy is an infectious disease. Just about everywhere in the world the same method is principally applied to find new medications against such diseases and to determine their value: natural or synthetic substances are looked for and found, are modified and become derivatives. When substances have proved to be effective in in vitro experiments, and with research animals, one tries to find out about their clinical effectiveness (Fig. 1(a)).

This is true for all infectious diseases, and in principle also for leprosy. But leprosy research involves the tremendous difficulty that the bacteria cannot be cultivated, and experiments therefore cannot be carried out in the usual manner. That is why we had to look for mycobacterial strains replacing Myco. leprae in in vitro and animal experiments (Fig. 1(b)).

We use various strains in vitro (Myco. marinum, Myco. avium, Myco. ulcerans, Myco. lepraemurium for instance, but also Myco. tuberculosis) in order to find out up to what extent they may be influenced by antimycobacterial substances. As far as animal experiments are concerned, the mouse footpad test introduced by Shepard and Rees surely is the most important aid we have in experimental leprosy research. This, however, should not keep us off looking for different methods. It was Eleanor Storrs who introduced armadillos in leprosy research, and there is no doubt today that Myco. leprae multiply in such animals. In Borstel we started using hedgehogs in animal trials. However, since the trials I should like to demonstrate today are not based upon the hedgehog as experimental animal, I shall not go into details with regard to these experiments.

(2) The experiments I shall talk about today were mainly carried out with Myco. marinum (substituting Myco. leprae) and mice. After intravenous infection Myco. marinum causes processes in mice affecting mainly tails, pads, ears, and the mucous membranes of mouth and nose (Fig. $2 \alpha$ ). In these experiments also appear the typical nodules which could be called "marinomas" instead of "lepromas" (Fig. 2 $\beta$ ). But marinomas and lepromas can hardly be distinguished; they also ulcerate, and they can easily be cured (Fig. $2 \gamma(\mathrm{a}),(\mathrm{b}),(\mathrm{c}),(\mathrm{d}))$. The tails 
regain their smooth appearance, but there may remain scars such as in human beings. Parts of the body which are already destroyed do of course not regenerate.

Histological examinations reveal formations which are typical for leprosy such

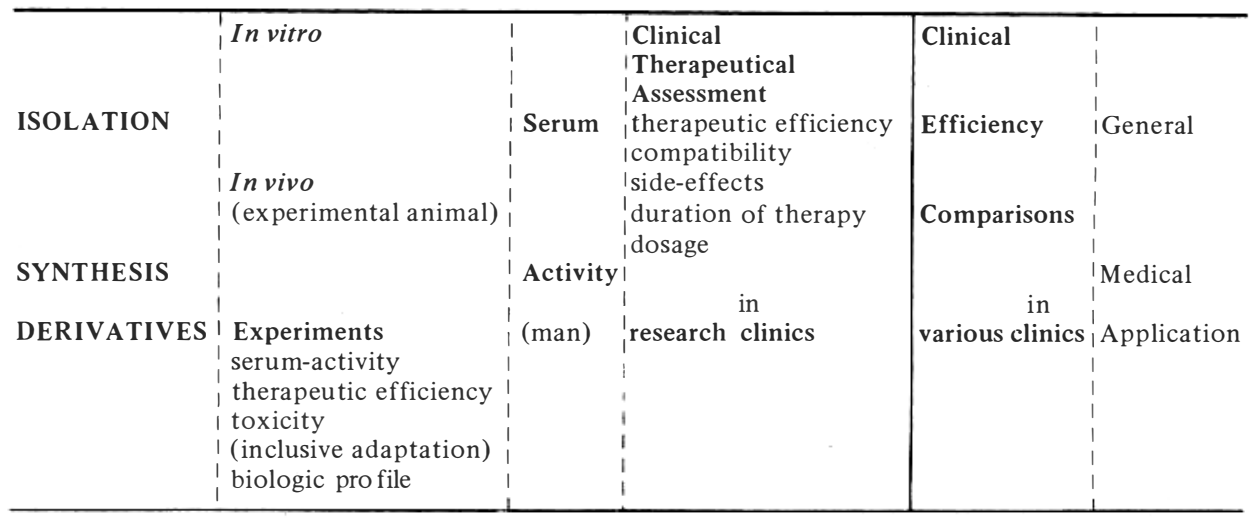

(a) Finding, synthesis, assessment of antimicrobic substances

\begin{tabular}{|c|c|c|c|c|c|}
\hline DERIVA TIVES & $\begin{array}{l}\text { In vitro } \\
\text { Substitutes for } \\
\text { Myco. leprae: } \\
\text { Myco. marinum } \\
\text { Myco. avium } \\
\text { Myco. ulcerans } \\
\text { Myco. lepraemurium } \\
\text { In vivo } \\
\text { footpad (mice) } \\
\text { armadillo } \\
\text { hedgehog } \\
\text { Experiments } \\
\text { serum-activity } \\
\text { therapeutic effect } \\
\text { toxicity } \\
\text { (inclusive adaptation) } \\
\text { biologic profile }\end{array}$ & $\begin{array}{l}\text { Serum } \\
\text { Activity } \\
\text { I } \\
\text { I } \\
\text { ( man) } \\
\text { ( } \\
\text { I } \\
\text { I }\end{array}$ & $\begin{array}{l}\text { Clinical } \\
\text { Therapeutic } \\
\text { Assessment } \\
\text { therapeutic efficiency } \\
\text { |compatibility } \\
\text { side-effects } \\
\text { duration of therapy } \\
\text { in } \\
\text { research clinics } \\
\text {, } \\
\text {, }\end{array}$ & $\begin{array}{l}\text { Efficiency } \\
\text { Comparisons }\end{array}$ & 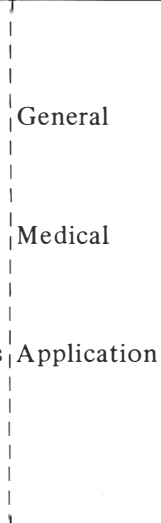 \\
\hline
\end{tabular}

(b) Finding, synthesis, assessment of anti-leprosy substances

Fig. 1 .

as the rarefaction of muscles, the replacement by fibroid infiltrates and encircling of nerves by fibrous tissue (Fig. 3(a), (b)).

(3) Of course we know that this model does not represent a case of leprosy produced in animals, but rather a mycobacteriosis similar to leprosy offering the great advantage that Myco. marinum is easily cultivable and virulent in mice. With the help of this method we found a number of substances which Shepard and Rees also considered to be the most effective in the mouse footpad test: 
Rifampicin (RAMP)

clof azimine (B663)

Isoniazid (INH)

Thioisonicotinic-acid-amides:

Ethionamide(Prothionamide (ETH/PTH)

Sulphones (DDS)

Long-acting-sulphonamides (LS)

Trimethoprim-sulphonamide preparations (TSP)

Ethambutol (EMB)

Streptomycin $(\mathrm{Sm})$

Kanamycin $(\mathrm{Km})$
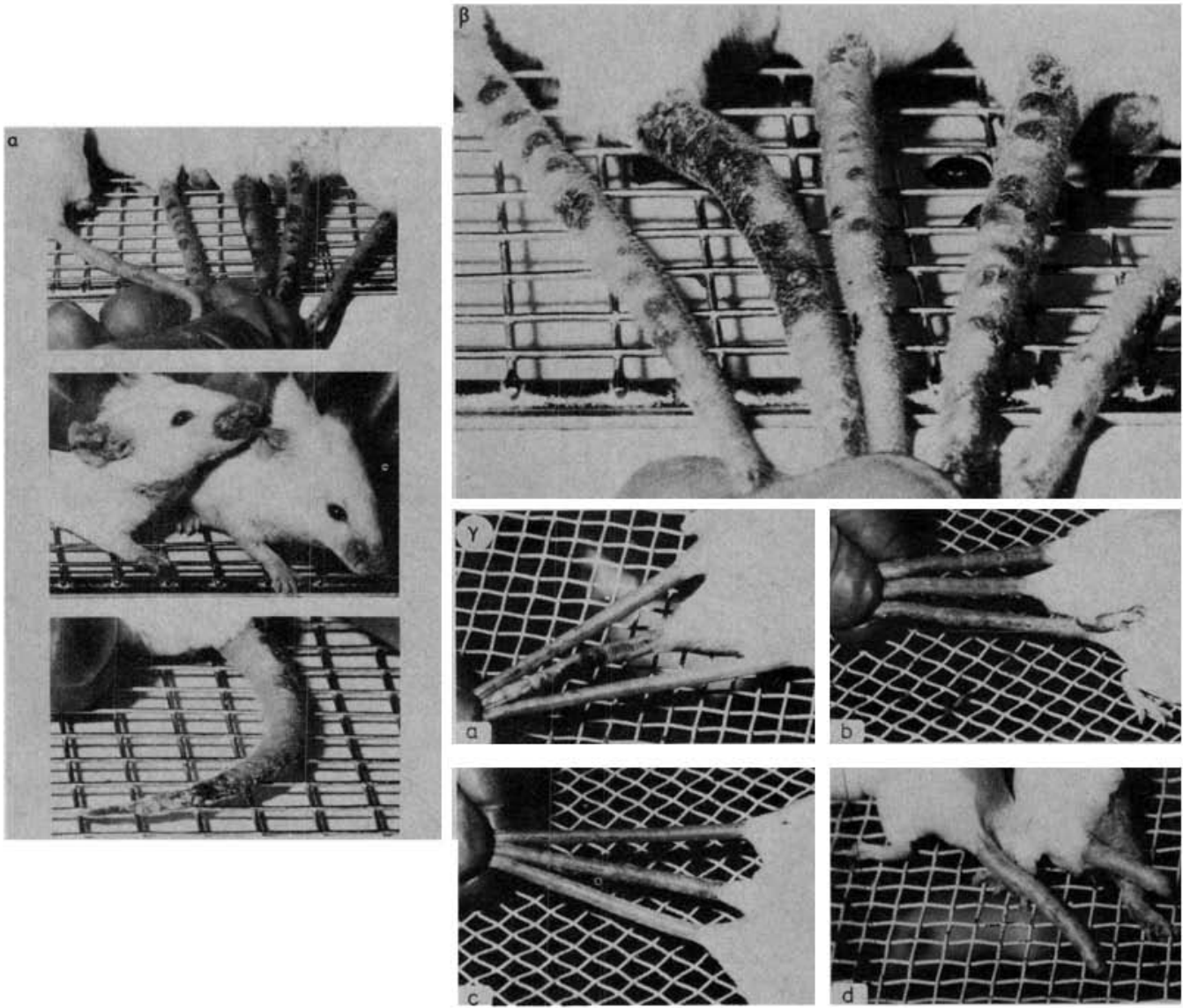

Fig. 2. 


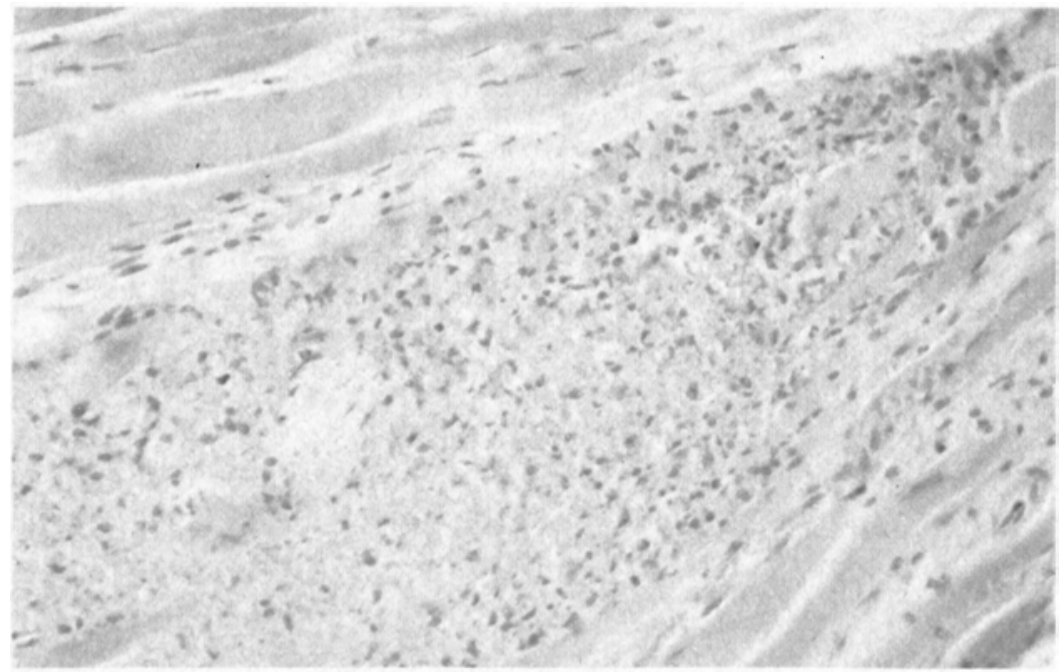

Fig. 3a.

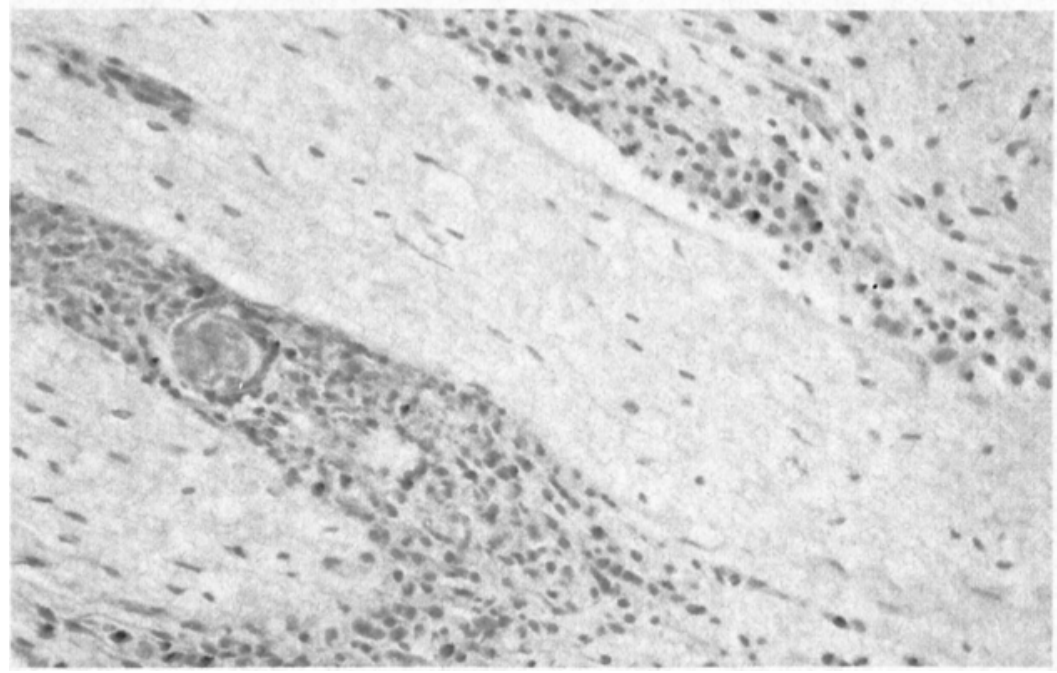

Fig. 3b.

(4) Figure 4 contains the data of a simple survival test carried out with this method (mouse-marinum). You notice the extraordinary efficacy of rifampicin depending on the dosage, which is typical for this medicament. The three substances of the sulphone and sulphonamide group do not show any particular differences. Long-acting sulphonamides, dapsone and Trimethoprimsulphonamide combinations have practically the same effect in these trials if used in different concentrations. From this point of view dapsone is the most effective of all. Only $50 \mathrm{mg}$ of dapsone are necessary to induce the same effect as $100 \mathrm{mg}$ of any other sulphonamide and sulphonamide-preparation. Combined therapy is often more effective than monotherapy. A few animal experiments carried out as 


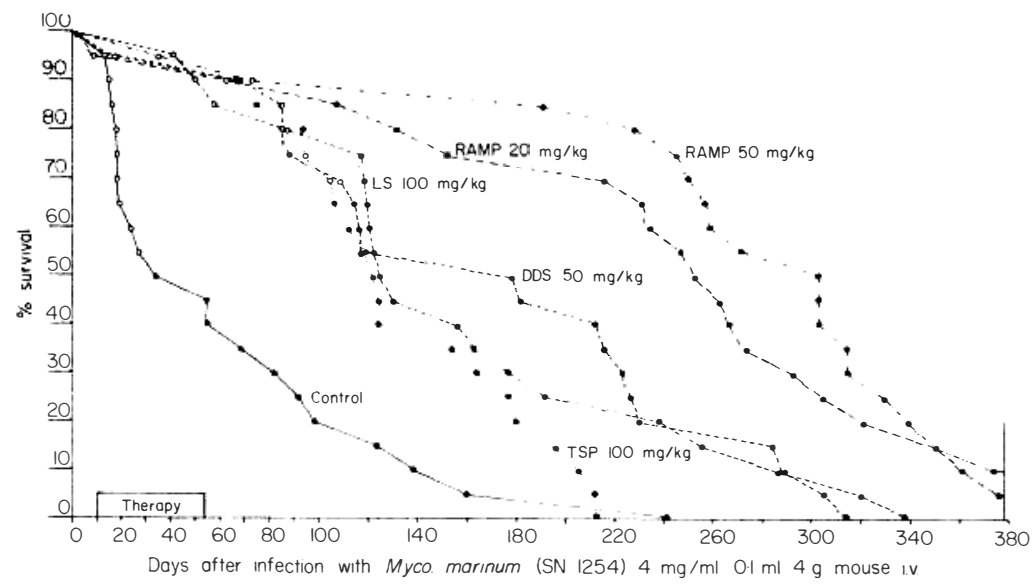

Fig. 4.

survival tests demonstrate this. Rifampicin can for instance be combined with Lamprene (B663) or ethionamide (Fig. 5(a), (b)). You notice once again that the combination is undoubtedly more effective than the single substance. But this is not always the case, not even if the substanc's used on their own prove to have a good effect (Fig. 5(c)).

A comparative test (Fig. 6) with Myco. tuberculosis (Middelburg) selected from a series of experiments demonstrates once again the great efficacy of combined treatment. Ten mg of rifampicin induce an effect which resembles that one obtained by combining isoniazid, prothionamide and dapsone (used as a fixed combination called Isoprodian and produced by Saarstickstoff-Fatol) although none of these substances used on their own in the dosage of the above mentioned combination has not even approximately the same effect as the combination. The activity of this combination can be considerably increased if rifampicin is added. A large number of experiments which cannot all be demonstrated here finally enabled us to give preference to a certain number of substances (Fig. 7). This choice was also based upon the aim that the substances to be applied in leprosy treatment should be as little toxic as possible and suitable for oral administration.

(5) Toxicity does not only depend on the chemical structure of the substance, but also on the administered dose as well as the duration of treatment. There do not exist many tests to demonstrate this. I have therefore chosen one which is not quite so common which, however, confirms very clearly my above statement:

For this sort of trial we preferably use hens, since there exist breeds today trained to lay one egg every day. These eggs are counted, and thus quantitative results can easily be obtained. Within a very short time rifampicin is capable of reducing the ovaries of these hens to such an extent that the animals are no longer able to produce eggs. At this stage of the experiment one could come to the false conclusion that rifampicin is an extremely dangerous substance. Many toxic phenomena are, however, nothing else but symptoms of adaptation. Here you can 


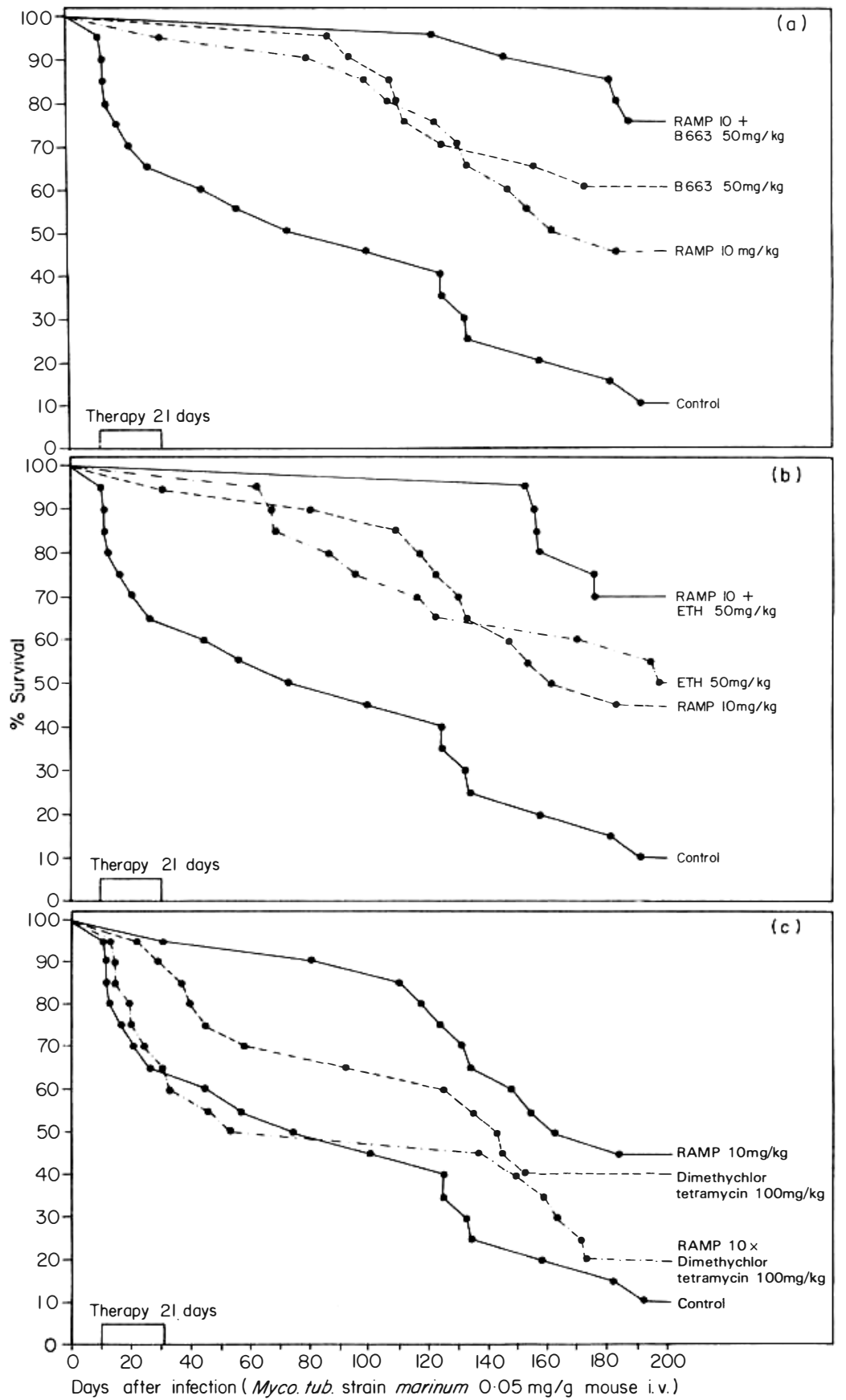

Fig. 5. 


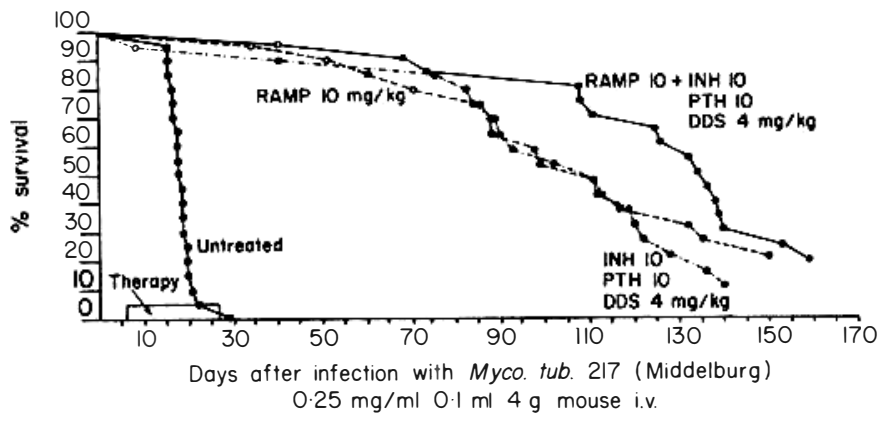

Fig. 6.

\section{Rifampicin-Combinations for Antimicrobial Chemotherapy}

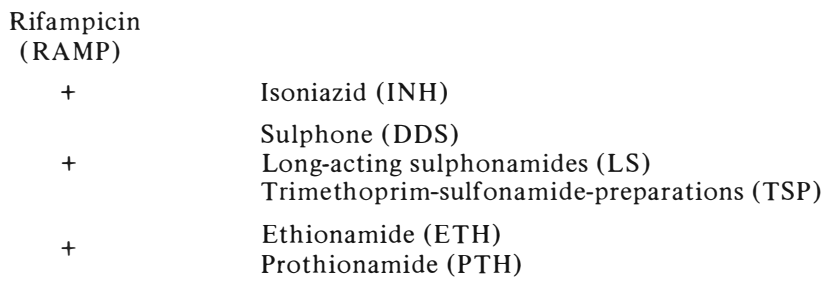

Combined therapy preferred at present:

RAMP + Isoprodian (INH, DDS, PTH)

Fig. 7.

see a chart (Fig. 8) in which each cross represents one laid egg. Rifampicin administered at a dose of $10 \mathrm{mg} / \mathrm{kg}$ does not induce the above phenomenon, whereas $100 \mathrm{mg} \mathrm{do}$, but only for a short time. During further administration of rifampicin the normal situation is restored. This ability of an organism to adapt itself to the toxic effect of certain substances is characteristic for many substances and is not always sufficiently taken into consideration. $500 \mathrm{mg}$ of rifampicin stop the production of eggs completely, which shows that the capacity of adaptation is restricted. I therefore think very accurate tests also referring to this phenomenon of adaptation are necessary before declaring a substance as being toxic. The occasional increase of transaminases under administration of rifampicin and the anaemia-inducing effect of dapsone which is now and then encountered probably are such phenomena of adaptation. But here again the problem of dosage should not be neglected.

(6) A problem regarding in vitro experiments is characterized by the terms

\section{bactericidal effect and bacteriostatic effect}

the inexact definition of which often leads to misunderstanding. Rifampicin for example is considered to have a bactericidal effect, a property which was also 


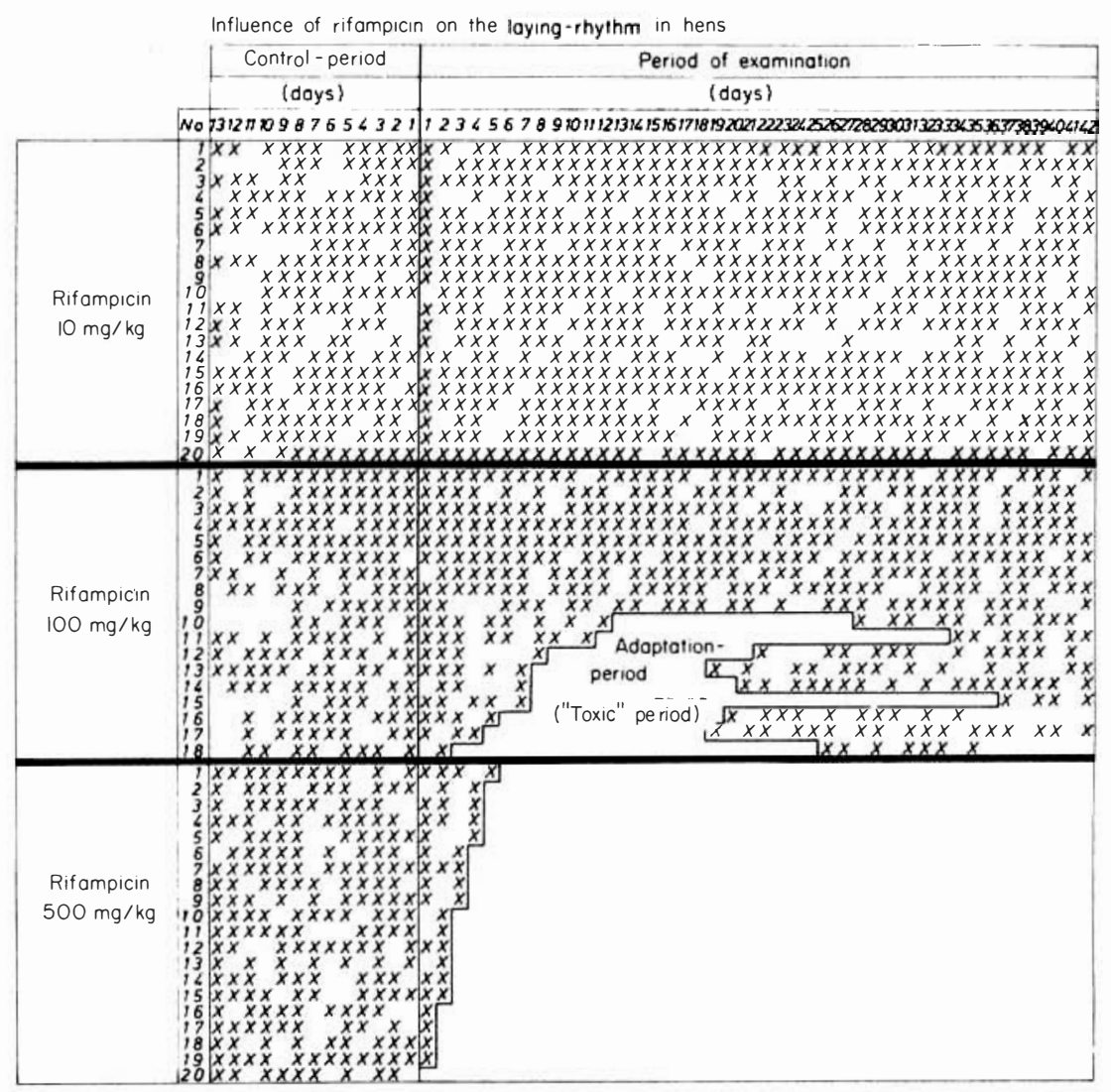

Fig. 8.

attributed to isoniazid in the past and even still is today. This matter is not only of theoretical interest, but also affects practical therapeutic methods and argumentation. Only a few substances exert a bactericidal action in vitro. These substances are therefore especially valuable for therapeutic purposes.

Figure 9 demonstrates the activity of rifampicin (RAMP), isoniazid (INH), streptomycin (SM), and ethambutol (EMB) against Myco. tuberculosis. If these substances in a certain concentration are allowed to act upon a culture within 6 days and if subcultures free from any antibacterial activity are set up afterwards, the bacteria start multiplying again. This shows that even doses up to $50 \mathrm{mg} / \mathrm{ml}$ of RAMP or INH are not able to exert a bactericidal effect, i.e. the killing of all bacteria. Only a dose of at least $5 \mathrm{mcg} / \mathrm{ml}$ of RAMP acting continuously over a period of 13 days leads to a bactericidal action in vitro. All other substances examined failed to show this result. Even if the duration of action is prolonged up to 20 days the results remain nevertheless unchanged.

Bacteriostatic substances thus cannot be rendered bactericidal even by highly increased doses and a prolonged duration of action. The typical effect of 


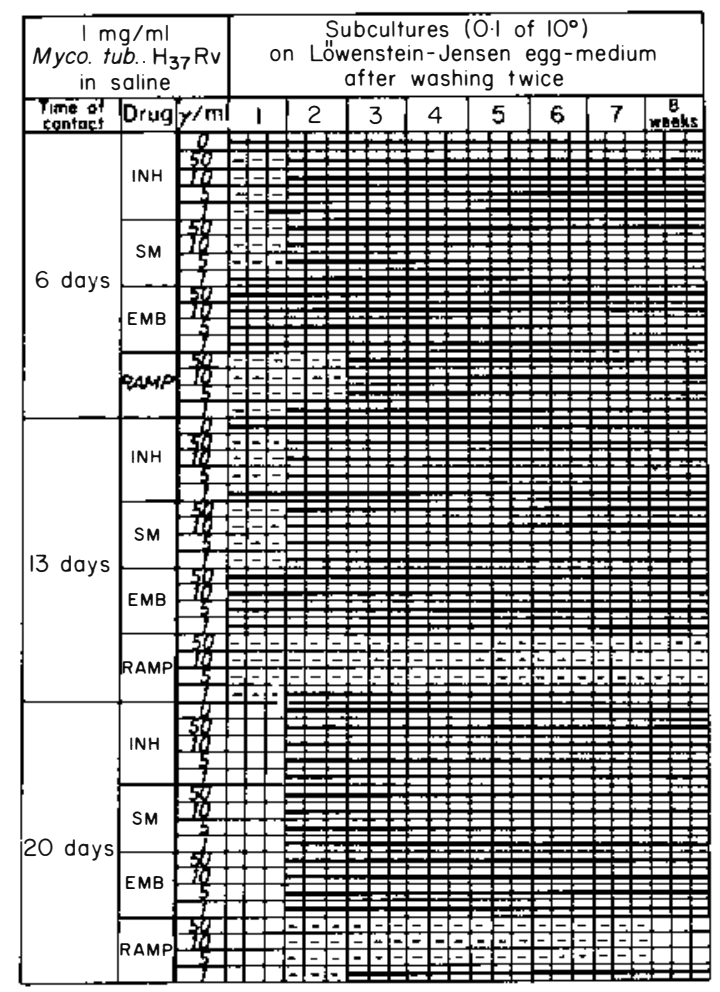

Fig. 9.

bactericidal substances only manifests itself when sufficient doses act for a long period of time. Under therapeutical conditions bactericidal substances prove to have only a bacteriostatic effect. This means that a potential bactericidal substance is far from being a bactericidal medicament. This difference must be emphasized in order to avoid false interpretation and methods of application.

Figure 10(a) and (b) show an experiment where combinations are used. Under the conditions chosen in the experiment of Fig. 10(a), neither rifampicin nor isoniazid, streptomycin, ethionamide or ethambutol are able to exert a total bactericidal effect in vitro if they are used as single substances. Similar negative results are obtained by combining ethionamide, ethambutol or streptomycin. The subcultures show a very heavy growth. A bactericidal effect is approached (single colonies which are countable instead of strong growth in the culture) if RAMP is used on its own, and even more if RAMP is combined with Sm or EMB.

A complete bactericidal effect is neither obtained by RAMP alone nor by $\mathrm{RAMP}+\mathrm{Sm}$ and RAMP + EMB, but rather by RAMP + ETH and RAMP + INH used as double combinations. All triple combinations used in this work and containing rifampicin therefore produce a bactericidal effect as long as INH or ETH are included. A bactericidal action without these two partners can only be achieved by using the combination RAMP $+\mathrm{Sm}+\mathrm{EMB}$. 


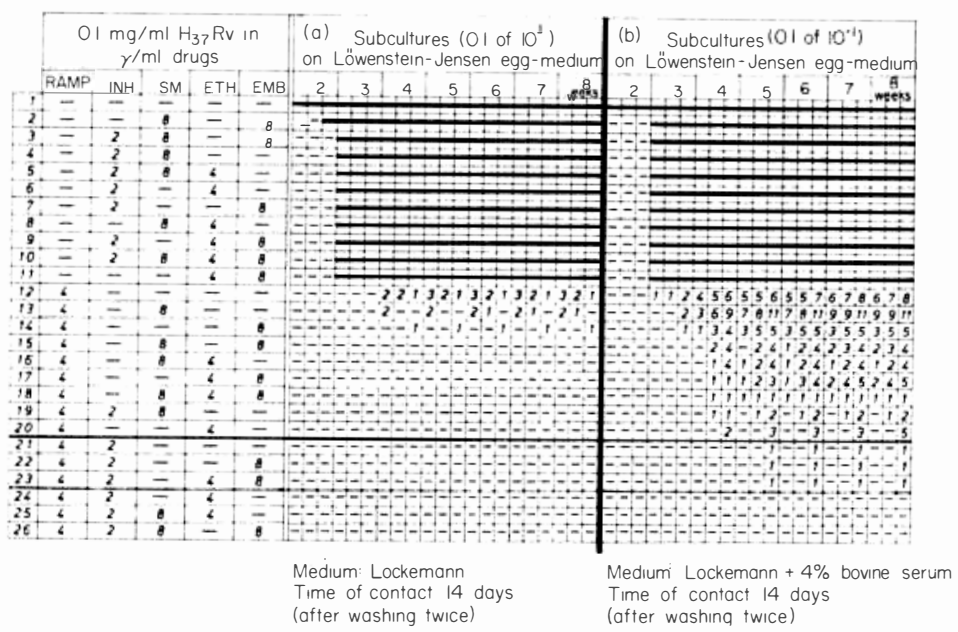

Fig. 10.

However, this result is not simply transferable to therapeutic conditions. Already a slight approach to in vivo conditions results in a reduction of the anti-bacterial effect. This is demonstrated in the experiment of Fig. 10(b) which was modified only be the addition of $4 \%$ of bovine serum to the primary culture medium.

Very good results are approached by using the following substances:

1. RAMP used on its own

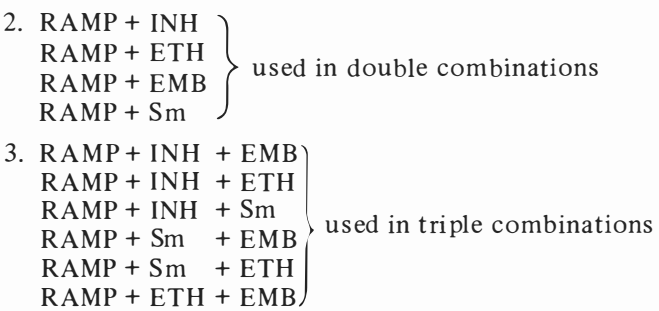

In this investigation only the following combinations exert a total bactericidal effect

$$
\mathrm{RAMP}+\mathrm{INH}+\mathrm{ETH}
$$

and

$$
\mathrm{RAMP}+\mathrm{INH}+\mathrm{EMB}+\mathrm{Sm}
$$

In the case of reduced sensibility it could be useful to administer-quadruple combinations:

$$
\begin{aligned}
& \mathrm{RAMP}+\mathrm{INH}+\mathrm{ETH}+\mathrm{EMB} \\
& \mathrm{RAMP}+\mathrm{Sm}+\mathrm{ETH}+\mathrm{EMB}
\end{aligned}
$$


It is thus a matter of fact that a bactericidal action can be induced in vitro by a potentially bactericidal substance if the latter is administered simultaneously with highly active bacteriostatics.

This example chosen from the tuberculosis field applies of course also to leprosy, but here the conditions appear to be less favourable, because the sensibility of Myco. leprae against those substances and combinations is probably less significant than that of Myco. tuberculosis. Nevertheless it can be considered as a matter of fact that well chosen RAMP combinations are more effective than RAMP on its own and that RAMP is more active than any antimycobacterial substance we have known in the past.

(7) Figure 11 shows an example for the importance of right dosage:

(a) The action of rifampicin at a dose of $50 \mathrm{mg} / \mathrm{kg}$ cannot be improved by adding $5 \mathrm{mg} / \mathrm{kg}$ or $10 \mathrm{mg}$ or $20 \mathrm{mg}$ of ethambutol. The differences are not significant. This could lead to the conclusion that the activity of rifampicin cannot be improved by combination with ethambutol. This, however, would be a false interpretation.

(b) If a very small dose of rifampicin $(2 \mathrm{mg} / \mathrm{kg})$ is combined with 5,10 , and $20 \mathrm{mg} / \mathrm{kg}$ of ethambutol, the effect of rifampicin even decreases. The choice of the wrong dose might (a) prevent the combination effect or (b) decrease the activity. When combining substances one should consider that the administration of too low doses is as dangerous as the choice of wrong proportions.

(c) If $10 \mathrm{mg} / \mathrm{kg}$ of rifampicin are combined with 5,10 , or $20 \mathrm{mg} / \mathrm{kg}$ of ethambutol, we can notice a combination effect, an increased activity due to the administration of higher doses of ethambutol. Not all doses are suitable for combinations.

(8) Another serious problem: Can we transfer the data obtained in vitro or by animal experiment to our clinical work? I wish to emphasize here that this cannot and must not be done! Mice differ from guinea-pigs. Guinea-pigs differ from rabbits, and rabbits differ from humans. Each macro-organism behaves in its own way.

One needs as connecting link (Fig. 1) the determination of the ser um activity in healthy persons or in patients, i.e. in human beings. In vitro experiments and animal experiments reveal whether a substance is effective or not and whether it induces any action in macro-organisms. But the data we require for the treatment of human beings can only be obtained by using material from human beings.

A few typical examples concerning the determination of human serum activity follow. Figure 12 shows the activity of several substances administered in monotherapy in doses applicable to human beings and used against Myco. marinum. Figure 13 demonstrates a determination of the serum activity of combinations. In this case the results obtained against Myco. marinum are juxtaposed against those obtained against Myco. tuberculosis. If rifampicin is combined with isoniazid, the effectiveness of rifampicin slightly decreases. By combining rifampicin with prothionamide the activity is remarkably improved. A better result is obtained if rifampicin is combined with INH and PTH. The best result is obtained by RAMP + INH + PTH + DDS. We combine rifampicin with isoniazid, with sulphones or sulphonamides or even sulphonamide combinations, with ethionamide or prothionamide depending always on the tolerance and special condition of the patient. 


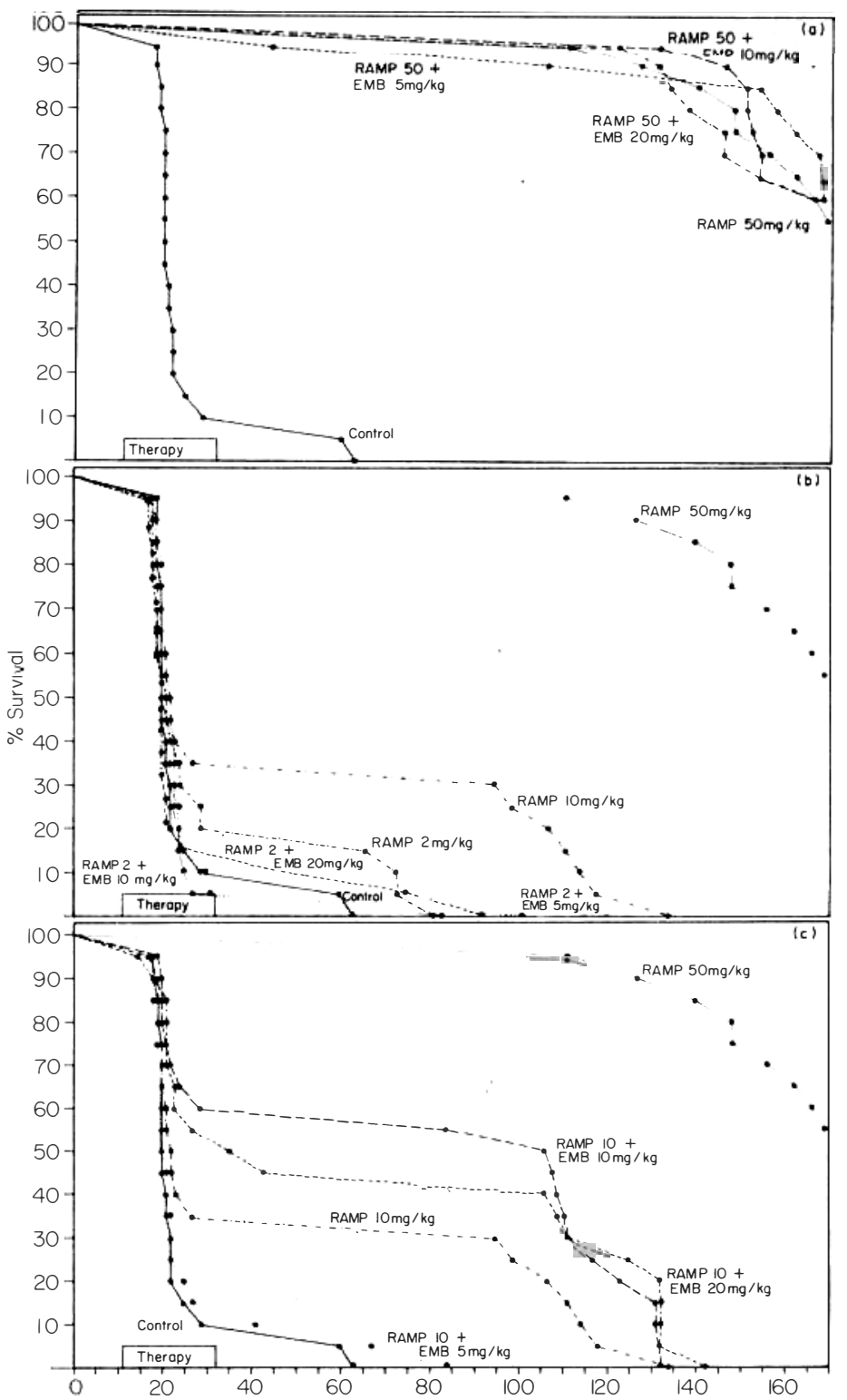

Days after infection with Myco tub. (Middelburg 217) $0.25 \mathrm{mg} / \mathrm{ml} \mathrm{O} \mathrm{Iml} 4 \mathrm{~g}$ mouse i.v

Fig. 11 .

(9) To decide the question whether the above mentioned increase of the antibacterial activity of special combinations can be explained as pharmacokinetic effects or is caused by combined activities against the germ, Havel has carried out in vitro experiments which will be published elsewhere in detail. They offer the 


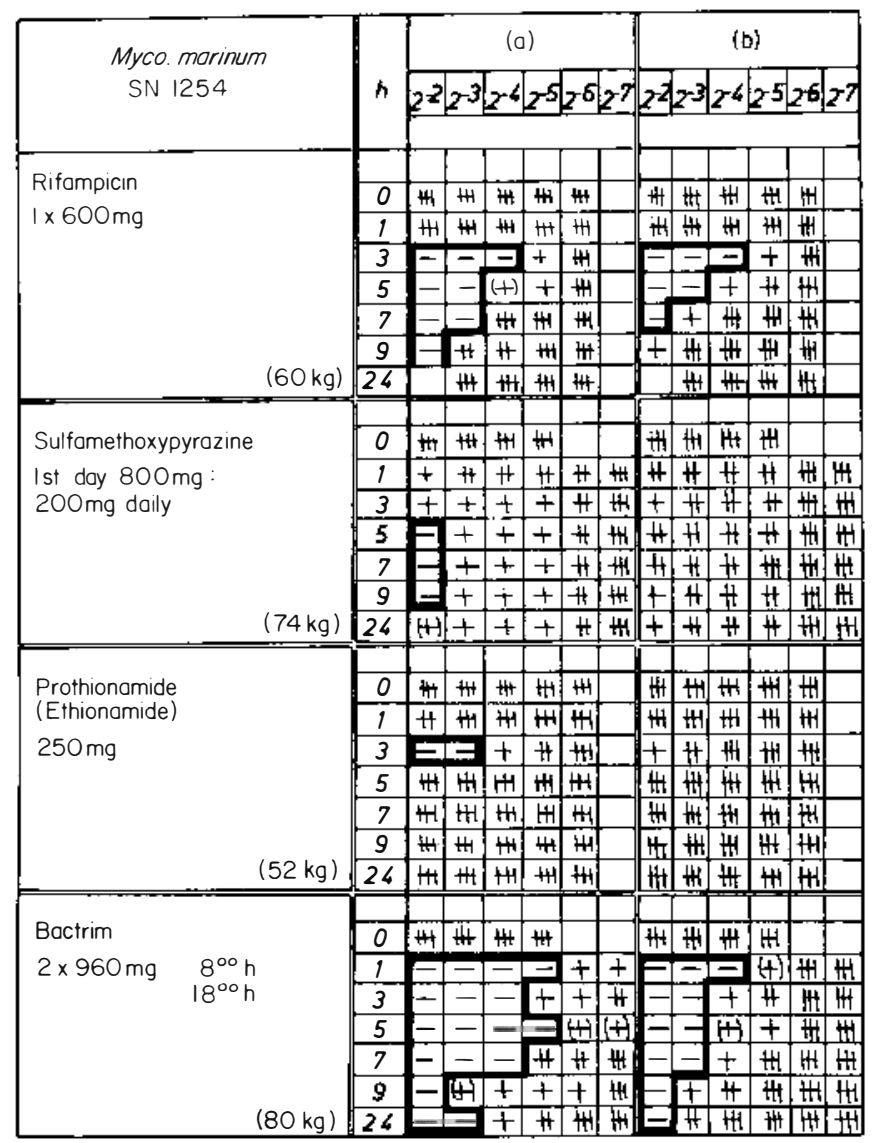

\section{Fig. 12.}

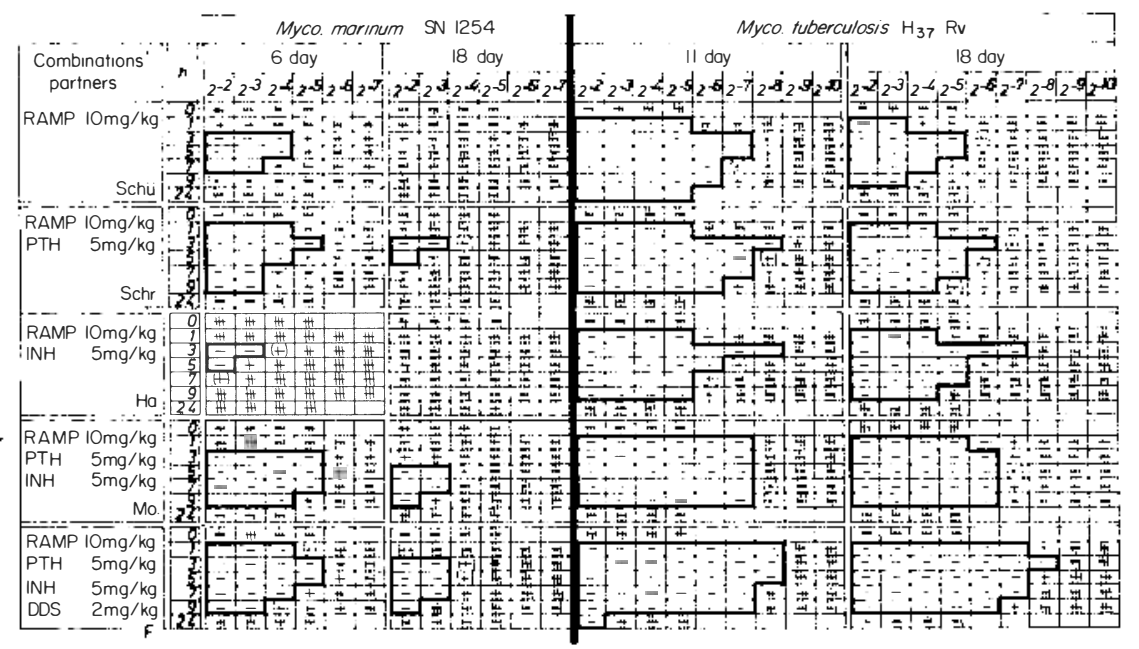

Fig. 13. 


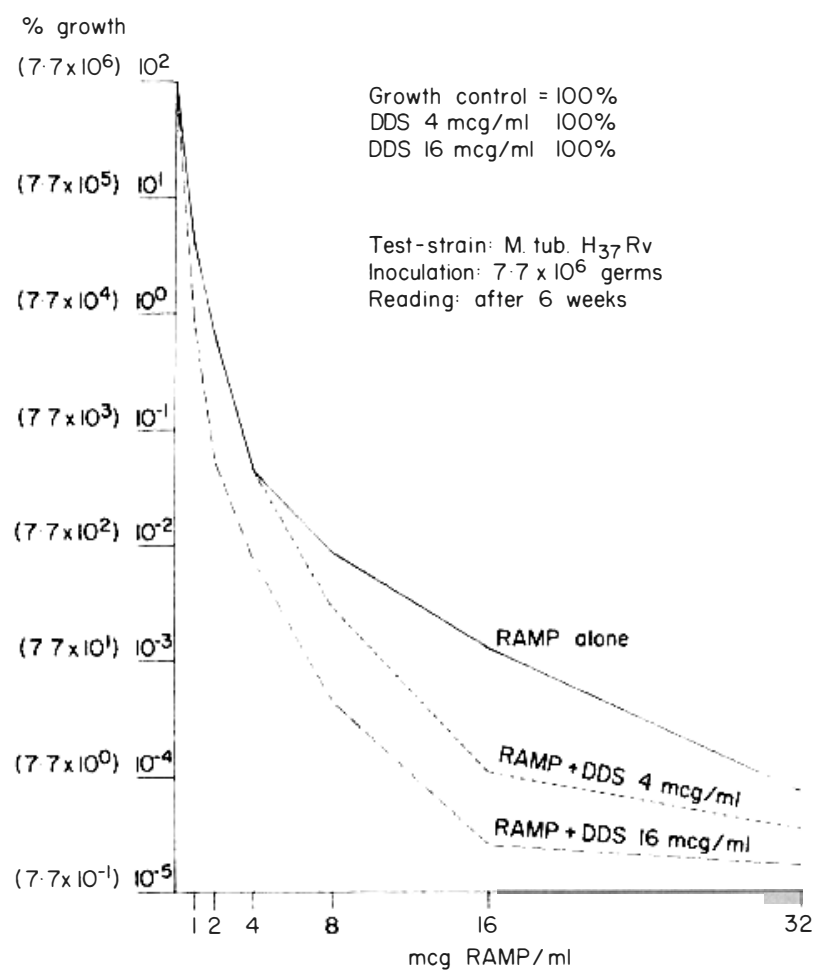

Fig. 14

advantage that each pharmacokinetic influence can be eliminated. Out of the great number of investigations I should like to present only one example (Fig. 14) where DDS alone at a dose of 4 and $16 \mathrm{mg}$ revealed no antibacterial effect and where the activity of rifampicin can be increased in the presence of dapsone. This effect of increase by dapsone is dose-dependent. This phenomenon can principally be seen also at remarkably lower doses of dapsone, e.c. when administered simultaneously with rifampicin and isoniazid.

(10) May I say here a few words referring to the clinical trial as such. I think that the time has come to set an end to finding effective therapeutics by means of trials lasting for years. If systems such as the determination of serum activity are integrated correctly into the total experimental system, we can predict the efficacy of a treatment which then only remains to be confirmed by the clinical results.

(11) We assume that the diseases induced by mycobacteria are comparable in spite of clinical differences, simply through the similarity of the disease-causing microbes. Chemotherapy is a causative therapy and is, as such, always directed against the pathogenic organism. This treatment is comparatively more effective against Myco. tuberculosis (Fig. 13) than against Myco. marinum (substituting Myco. leprae), but nevertheless proves to be more successful than the application 


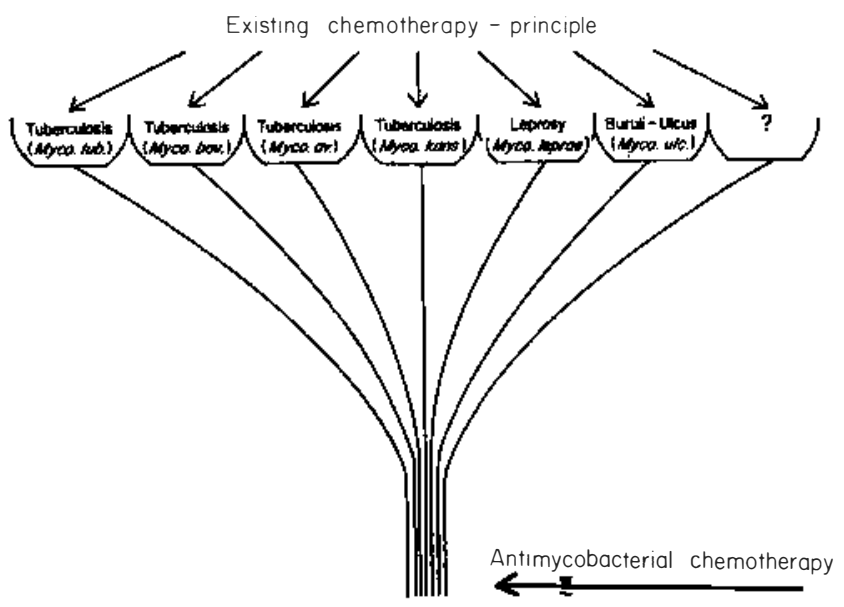

Fig. 15.

of all substances and combinations we have known up to now. We may therefore well apply this therapy with similar success against leprosy as well as tuberculosis. Our intention is to render leprosy treatment as effective, as short and at the same time as non-toxic as possible. We aim at making leprosy treatment an ambulatory treatment and try to accomplish that such a therapy will be effective not only against tuberculosis, but also against all diseases induced by mycobacteria. Figure 15 is supposed to show this in diagram. In other words: our objective is to find a universally effective antimycobacterial therapy. 